\title{
Fullerenes production by electric arc pyrolysis of methane in an AC three-phase plasma torch
}

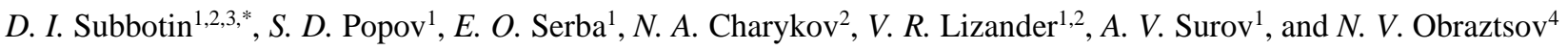 \\ ${ }^{1}$ Institute for Electrophysics and Electric Power of the Russian Academy of Sciences (IEE RAS), St. Petersburg, Russia \\ ${ }^{2}$ St. Petersburg State Technological Institute (Technical University), St. Petersburg, Russia \\ ${ }^{3}$ St. Petersburg National Research University of Information Technologies, Mechanics and Optics, St. Petersburg, Russia \\ ${ }^{4}$ Peter the Great St. Petersburg Polytechnic University, Saint-Petersburg, Russia
}

\begin{abstract}
The article deals with a high-voltage three-phase AC plasma torch working as a part of a plasma-chemical facility. The plasma torch consists of three electric arc channels and three rod copper electrodes. The initial breakdown occurs with high voltage $(10 \mathrm{kV})$ provided by a high voltage power supply. The electric arc plasma oxygen-free pyrolysis of methane was realized on the facility. The fullerenecontaining fraction was extracted from the carbonaceous material by extraction with orthoxylene. The produced carbon-black and the selected extract were analyzed by modern methods of physical and chemical analysis: scanning electron microscopy, X-ray phase analysis, IR spectroscopy.
\end{abstract}

\section{Introduction}

In the modern context of traditional fossil fuels depleting and global warming, plasma systems remain one of the most promising technologies in many large-scale industries, such as the elimination of pollution and recycling (household, medical, biological, toxic or hazardous waste) [1], energy production (combustion of low-calorie fuels, igniting, starting and supporting of coal-fired power plants, pyrolysis, fossil cracking and gasification and/or cracking of renewable fuels) [2], production of materials (metal melting, reduction and regeneration, sealing of particles, nanoparticle synthesis) [3].

Since discovery of fullerenes in 1985, it has been shown that fullerenes can be synthesized by various methods. These methods include synthesis using laser ablation, arc discharge, arc plasma jet, concentrated solar radiation, resistive and inductive heating, and methods based on the combustion of hydrocarbons. Over the past 25 years due to the unique properties of fullerenes their applications for materials based on them were proposed in many fields such as science, optics, chemistry, electrochemistry, biology, medicine, pharmaceutics, cosmetology, etc.

The success of these applications depends on the ability to produce high-quality fullerenes in a sustainable and environmentally friendly manner in a large-scale production. Prices for the most popular C60 fullerene range from $\$ 25-50 / \mathrm{g}$ and remain virtually unchanged for the last 20 years, which indicates the relevance of developing of more energy-efficient methods for their production. The methods based on plasma technologies provide ample opportunities and options for the practical implementation of this idea.
The production of fullerenes in the arc discharge, which is one of the numerous plasma methods, despite the fact that a number of other synthesis methods have already been developed, still remains one of the most popular and widely used [4]. This is due to its high performance and relative simplicity. The direct contact of the electrodes is necessary only at the initial stage of the process in order to ignite the arc. Then the electrodes are separated by a set distance, which must be kept constant to ensure the stable arc burning. For this purpose, there is a device moving one of the electrodes in the arc facilities. Design of arc facilities can be different: with horizontal or vertical arrangement of electrodes, using two or more electrodes of various shapes and sizes, with or without blowing buffer gas into the arc zone, with a different set of control devices and process automation [5]. Evaporation occurs mainly on the anode if the arc is powered by DC. Carbon vapor, carried away from the arc, is condensed on the surface of a special cooled chamber. It is clear from the analysis of numerous publications that the content of fullerenes in the products of arc synthesis can vary greatly from fractions up to several tens of percent. The mixture of fullerenes extracted from soot is mostly C60 (about 90\%) and C70 (about 10\%), and the content of higher fullerenes is very small [6]. The rate of formation of fullerenes in the arc process, and hence their quantitative yield, is influenced by many factors, in particular, such as: type of buffer gas and its pressure [7], electrical characteristics of the arc and the nature of its binding to the anode [8], plasma temperature and concentration of electrons in it [9], the conditions for the removal of carbon vapor from the arc zone and its further condensation [10].

\footnotetext{
* Corresponding author: subbotin1987@mail.ru
} 
The synthesis of fullerenes and other carbon nanostructures can be carried out not only in the DC arc, but also in a pulsed arc discharge. A detailed description of the facility for the fullerene synthesis using this technology is presented in [11]. The ignition of a pulsed arc between two graphite electrodes occurs when voltage is applied to them from a special source of voltage pulses with an adjustable amplitude and duty cycle. The electrodes are located in a tube of quartz glass, which in turn is inside the tube furnace, capable of heating up to $800-1200^{\circ} \mathrm{C}$. This method requires adequate vacuum equipment, it is relatively energy intensive and costly. It was also found that successful synthesis of fullerenes can be carried out not only with the help of a traditional DC arc or a current of industrial frequency, but also with higher-frequency plasma $(44-440 \mathrm{kHz})$ in a helium flow at atmospheric pressure $[12,13]$. The results of the comparative study of the fullerene synthesis in a helium flow at atmospheric pressure using three types of arc power supply are given in [14]: DC and AC with a frequency of $50 \mathrm{~Hz}$ or $44 \mathrm{kHz}$. The formation of fullerenes was most effective when the arc was powered with a current of $44 \mathrm{kHz}$. The maximum yield of fullerenes was 9 wt.\% in a chamber of $15 \mathrm{~cm}$ in height and $20 \mathrm{~cm}$ in diameter.

The authors of [13] described a method for increasing of plant output using a combination of DC and $\mathrm{AC}$ in the kilohertz frequency range. In [15] the high-frequency arc supply voltage $(44 \mathrm{kHz})$ was modulated with a low-frequency voltage in the range of $0-10 \mathrm{kHz}$. It has been established that with the introduction of low-frequency modulation of the highfrequency arc supply voltage, the fullerene content increases. At a resonant modulation frequency of 5.3 $\mathrm{kHz}$, the fullerene content reached $8.4 \%$, while without modulation it was $5 \%$.

A significantly higher productivity for fullerenes was obtained on a facility with an AC three-phase arc plasma torch $[16,17]$. In this facility, carbon plasma is formed already in the arc between three graphite electrodes, and after that it is additionally enriched with carbon by supplying of a mixture of inert gas with fine graphite. The facility productivity is $1 \mathrm{~kg} / \mathrm{h}$ of carbon-black containing up to $5 \%$ fullerenes at a plasma torch electric power of $260 \mathrm{~kW}$. Among the advantages of this facility is that it is capable of continuously operating in a closed cycle for a long time without throwing out any byproducts into the environment.

The method of fullerene synthesis in the flame during the combustion of hydrocarbons was also intensively developed simultaneously with the arc method. The production of fullerenes in a flame is one of the most promising methods for solution the problem of largescale production $[18,19]$. Unlike the electric arc method of graphite evaporation, the method of synthesis in a flame is characterized by continuity, efficiency and adaptability. Despite the fact that the share of hydrocarbon conversion to fullerenes is small, the main focus of development of this method was precisely the increase in production [20]. It was found that the use of benzene as a fuel leads to the highest yield of fullerenes compared with toluene and other hydrocarbons [18, 21].

\section{Experimental part}

The following materials were used in the experiments: argon (no less than 99.994 vol.), Methane (98.9\% vol.) and orthoxylene (no less than $99.5 \%$ mass).

The study of soot samples was carried out on a TESCAN VEGA3 SBH scanning electron microscope. Bruker D2 Phaser powder diffractometer was used in order to determine the phase composition of electric arc pyrolysis products. IR spectra were recorded on a Shimadzu IRTracer-100 spectrometer. A spectrophotometer from the analytical laboratory of SPbGASU was used for determination of fullerene content in the orthoxylene extract.

The experimental facility comprises the three-phase high-voltage plasma torch, power supply system, cooling system and gas supply system. The plasma torch is made of steel in the form of two perpendicularly intersecting cylinders (Figure 1). The facility is equipped with sensors to monitor the gas flow and electrical current parameters. The electrode system of the plasma torch consists of three replaceable rod copper electrodes with fluoroplastic insulators at the base. Protective gas (argon) is supplied to the bases of the electrodes; a mixture of plasma gas with hydrocarbon (methane) is fed at some distance from the ends of the electrodes. The electrodes are located at three ends of the plasma torch cross body. The reaction products are cooled in a water cooler (Figure 2).

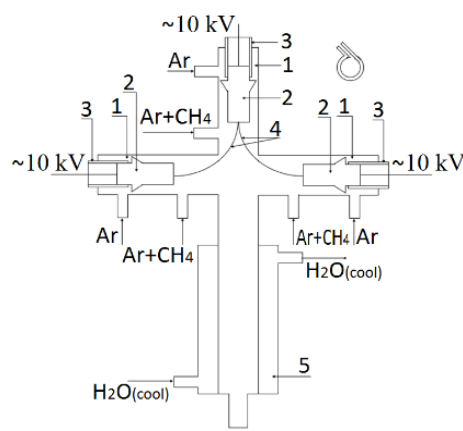

Fig. 1. Diagram of the experimental installation: 1 - electric arc channel, 2 - electrode, 3 - fluoroplastic insulator, 4 - electric arc trajectories, 5 - water cooler.

A $50 \mathrm{~Hz}$ high-voltage power supply consists of three current-limiting reactors, reactance compensator, step-up transformer and automatic switchboard. Initial breakdown between an electrode and a wall of the electroarc channel occurs on account of high voltage of no-load running $(10 \mathrm{kV})$. An electric arc moves along the electroarc channel due to tangential feed of the plasma-forming gas until it interlocks with another electric arc of another electroarc channel. Then reignition of the electric arc occurs in the hightemperature zone (approximately in the centre of the channel) between two electrodes through both channels at once. The current-limiting reactors stabilize burning of the electric arc and facilitate the second breakdown when the electric current passes through zero. In the given circuit design, the capacitance compensator of reactance 
rises the power factor $(\varphi \geq 0.99)$. In detail a power supply of the similar plasma torch is presented in [22].

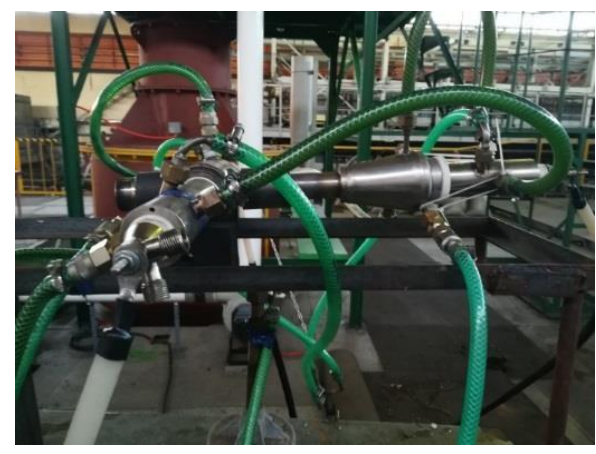

Fig. 2. Plasma torch.

Pyrolysis lasted 3 minutes, the temperature in the gas-discharge chamber was about $4000 \mathrm{~K}$. In all experiments, argon was supplied to the area of the electrodes with a total mass flow rate $\mathrm{GAr}=3 \mathrm{~g} / \mathrm{s}$. Argon was also supplied to the arc burning zone with a flow rate $\mathrm{GAr}=0.5 \mathrm{~g} / \mathrm{s}$. The power of the plasma torch was $\sim 10 \mathrm{~kW}$.

\section{Results and discussion}

Figure 3 represents micrographs of soot sample. As can be seen from the figure, the carbon black has a developed external surface, which may be relevant for its application in industry. According to $\mathrm{x}$-ray diffractometry of soot samples (Figure 4), the degree of crystallinity was estimated. The highest value of the degree of crystallinity was about $66 \%$. The high degree of crystallinity can be explained by the presence of various modifications of graphite, as well as other crystalline forms of carbon, such as fullerenes and fulleroid nanomaterials.

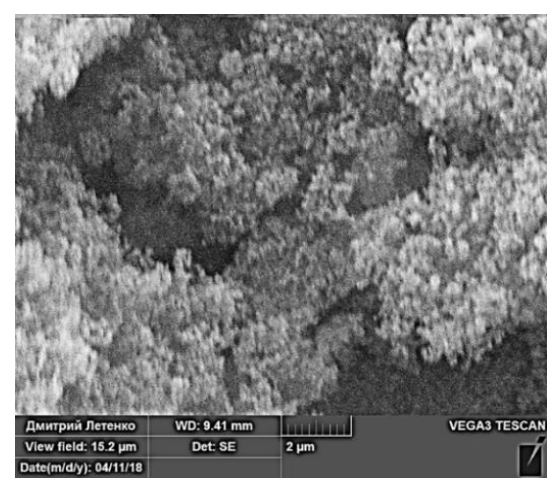

Fig. 3. Soot micrographs (magnification 17000x).

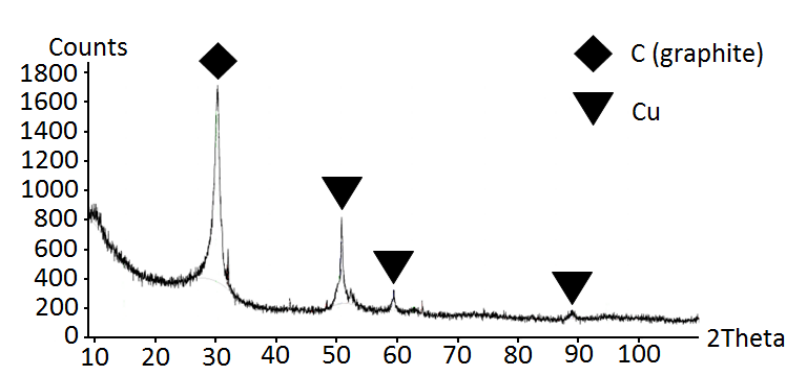

Fig. 4. Soot X-ray Diffraction Pattern.

The IR spectra of the carbon black sample were recorded. Figure 5 shows the spectrum of soot. It can be seen from the spectrum that the soot contains various hydrocarbons (bands in the region of 2800-3100, 600$800,1300-1600 \mathrm{~cm}-1)$, which indicates that the decomposition of hydrocarbons into carbon and hydrogen was incomplete. The soot samples were subjected to extraction with o-xylene (magnetic stirring and treatment with an ultrasonic bath at room temperature for an hour). The spectrum in the visible and ultraviolet regions is shown in Figure 6. According to the data of electron spectroscopy, the content of fullerenes in soot was estimated. The following formulas [23] (mg/l) were used to estimate the concentration of fullerenes (see Table 1):

$$
\begin{aligned}
& C\left(C_{60}\right)=13.1\left(D_{335.7}-1.81 \cdot D_{472}\right) \\
& C\left(C_{70}\right)=42.5\left(D_{472}-0.0081 \cdot D_{335.7}\right)
\end{aligned}
$$

The electronic spectrum of the orthoxylene extract is shown in Figure 6 . The region of the spectrum with a maximum optical density along the fullerene $\mathrm{C}_{60}$ is indicated by a vertical line.

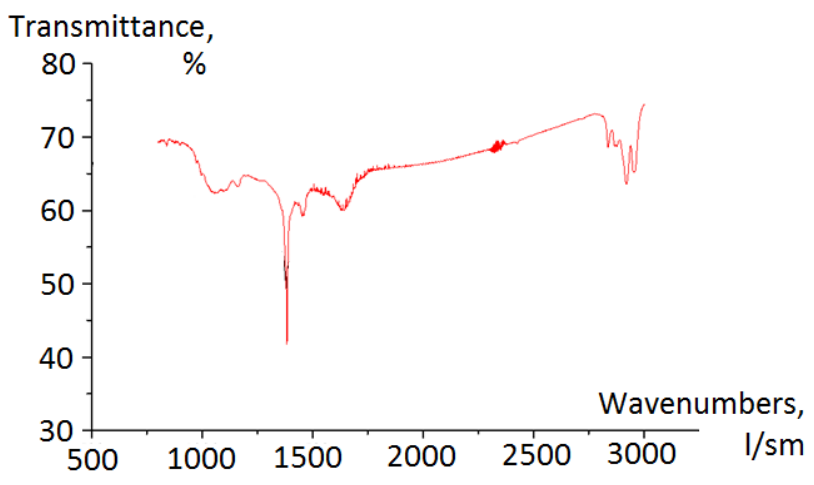

Fig. 5. IR spectra of soot.

Table 1. Fullerene concentration.

\begin{tabular}{|c|c|c|c|c|c|c|c|c|}
\hline № & $\mathrm{D}_{335.7}$ & $\mathrm{D}_{472}$ & $\begin{array}{c}\mathrm{C}\left(\mathrm{C}_{60}\right), \\
\mathrm{mg} / \mathrm{l}\end{array}$ & $\begin{array}{c}\mathrm{C}\left(\mathrm{C}_{70}\right), \\
\mathrm{mg} / 1\end{array}$ & Dilution & $\omega\left(\mathrm{C}_{60}\right), \%$ & $\omega\left(\mathrm{C}_{70}\right), \%$ & $\begin{array}{c}\text { Ratio } \\
\mathrm{C}_{60} / \mathrm{C}_{70}\end{array}$ \\
\hline 1 & 1.00 & 0.09 & 10.96 & 3.46 & 10 & 1.10 & 0.35 & 3.17 \\
\hline
\end{tabular}




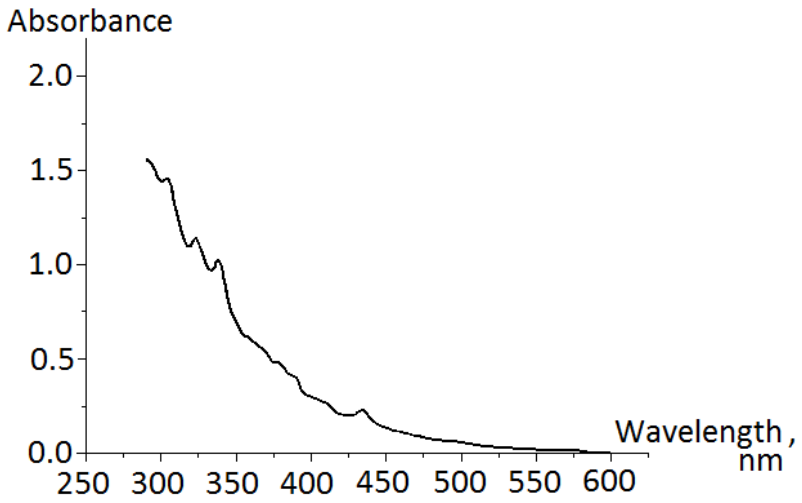

Fig. 6. Electronic spectra of soot extracts.

\section{Conclusions}

Thus, nanocarbon material with submicron particle sizes was produced by the method of oxygen-free electrical arc pyrolysis of methane. The resulting carbon black contained particles of graphite $(66 \%)$ and amorphous carbon (34\%), as well as light fullerenes in amounts up to $3 \%$. IR spectroscopy showed reflexes typical of $\mathrm{C}-\mathrm{C}$ bonds in graphite and $\mathrm{C}-\mathrm{H}$ in polynuclear hydrocarbons. The spectrum is characterized by some peaks in the near UV region, in particular, $\lambda=337 \pm 2$ $\mathrm{nm}$, characteristic of light fullerenes. X-ray diffractometry showed the presence of graphite and amorphous carbon. On these grounds it can be assumed that this method can be applied as a low-cost and effective method for the synthesis of fullerenes.

This work was supported by Programs of Fundamental Research of the Presidium of the Russian Academy of Sciences No. 7.

\section{References}

[1] A.A. Safronov, O.B. Vasileva, Yu.D. Dudnik, V.E. Kuznetsov, V.N. Shiryaev, D.I. Subbotin, N.V. Obraztsov, A.V. Surov, V.E. Popov High Energy Chemistry 52(4), 319-323 (2018)

[2] V.E. Popov, D.I. Subbotin, A.V. Surov, S.D. Popov, E.O. Serba, E.P. Godina, A.A. Kiselev, J. Phys.: Conf. Ser. 1243 012010, (2019)

[3] F.G. Rutberg, V.A. Kolikov, V.N. Snetov, D.I. Subbotin, A.I. Zhernovoi, I.A. Cherepkova, S.V. Dyachenko, High Temperature 54(2), 170-174 (2016)

[4] G.N. Churilov, Fullerenes, Nanotubes and Carbon Nanostructures 16(5-6), 395-403 (2008)

[5] R.E. Haufler, Electrochem. Soc. Proc. 94(24), 50-67 (1994)

[6] G.N. Churilov, Instruments and Experimental Techniques 43(1), 1-10 (2000)

[7] N.I. Alekseyev, G.A. Dyuzhev, Technical Physics. The Russian Journal of Applied Physics 46(10), 1247-1255 (2001)

[8] D.V. Afanasev, A.A. Bogdanov, G.A. Dyuzhev, A.A. Kruglikov, Technical Physics. The Russian Journal of Applied Physics 42(2), 234-237 (1997)
[9] G.N. Churilov, FTT 44(3), 406-409 (2002)

[10] M.M. Kasumov, V.V. Pokropivny, Technical Physics. The Russian Journal of Applied Physics 52(7), 956-958 (2007)

[11] T. Sugai, H. Omote, S. Bandow, N. Tanaka, H. Shinohara, Journal of chemical physics 112(13), 6000-6005 (2000)

[12] G.N. Churilov, I.V. Osipova, G.A. Glushenko, N.G. Vnukova, A.L. Kolonenko, A.I. Dudnik, W. Krätschmer, Carbon 62, 389-392 (2013)

[13] G.N. Churilov, P.V. Novikov, V.A. Lopatin, N.G. Vnukova, N.V. Bulina V.E. Tarabanko Carbon 40(6), 891-896 (2002)

[14] N.V. Bulina, V.A. Lopatin, P.V. Novikov, N.G. Vnukova, G.N. Churilov, W. Krätschmer, NATO Security through Science Series A: Chemistry and Biology 3, 269-274 (2006)

[15] G.N. Churilov, I.V. Osipova, P.V. Novikov, V.A. Lopatin, A.S. Krylov, E.A. Petrakovskaya, Y.V. Tomashevich, Fullerenes Nanotubes and Carbon Nanostructures 18(4-6), 584-589 (2010)

[16] L. Fulcheri, Y. Schwob, F. Fabry, G. Flamant, L.F.P. Chibante, D. Laplaze, Carbon 38(6), 797-803 (2000)

[17] F. Fabry, T.M. Gruenberger, J.G. Aguilar, H. Okuno, E. Grivei, N. Probst, L. Fulcheri, G. Flamant, J.C. Charlier, Proc.NSTI-Nanotech 2, 201-204 (2005)

[18] J.B. Howard, A.L. Lafleur, Y. Makarovsky, S. Mitra, C.J. Pope, T.K. Yadav, Carbon 30 1183-1201

[19] Z.A. Mansurov, Combustion, Explosion, and Shock Waves 41(6), 727-744 (2005)

[20] H. Takehara, M. Fujiwara, M. Arikawa, M.D. Diener, J.M. Alford, Carbon 43(2), 311-319 (2005)

[21] F. Goel, P. Hebgen, J.B.V. Sande, J.B. Howard Carbon 40, 177-182 (2002)

[22] Ph. Rutberg, Gh. Nakonechny, A. Pavlov, S. Popov, E. Serba, A. Surov, J.Phys. D: Appl. Phys. 48, 245204 (2015)

[23] A.N. Ponomarev, M.E. Yudovich, V.A. Nikitin, D.V. Nikitin, V.T. Barchenko, V.N. Sobol', K.B. Strel'nikov, N.A. Charykov, A.I. Myshkov, V.I. Sergeev, Molecular Spectroscopy 88(2), 230-232 (2000) 